Научная статья

УДК 130.2

DOI: 10.18101/1994-0866-2021-4-62-69

\title{
ФУНКЦИОНАЛЬНАЯ ПРОТИВОРЕЧИВОСТЬ ПЕРЕВОДА В СОЦИОКУЛЬТУРНЫХ ПРАКТИКАХ
}

\author{
(C) Волкова Анна Александровна \\ ассистент, \\ Российский государственный гуманитарный университет \\ Россия, 125993, г. Москва, Миусская площадь, 6 \\ mymailmymail1994@mail.ru
}

\begin{abstract}
Аннотация. В статье рассматриваются функции перевода в межкультурных, межъязыковых формах коммуникации, а также в системе социальных отношений. Постколониальная оптика позволяет рассмотреть функциональность перевода в условиях языковой несоизмеримости. Межкультурная коммуникация демонстрирует разграничительную функцию перевода. Рассматривая действие перевода в системе социальных связей, мы прослеживаем противоположную функцию перевода: возможность выстраивания единого коммуникативного пространства при разности интересов участников коммуникации. Противоречивость функций перевода заключается в том, что, с одной стороны, перевод способствует возможности взаимодействия, в то же самое время перевод представляет собой границу, разделяющую участников коммуникационного процесса. Тем не менее разнонаправленность функций перевода способствует сохранению возможности самой коммуникации как в условиях межъязыкового общения, так и внутри одного языка.

Ключевые слова: перевод, коммуникация, противоречивость функций перевода, перевод интересов, эпистемологический перевод.
\end{abstract}

\section{Для цитирования}

Волкова А. А. Функциональная противоречивость перевода в социокультурных практиках // Вестник Бурятского государственного университета. Философия. 2021. Вып. 4. С. 62-69.

\section{Введение. Противоречивость перевода}

Термин «перевод» обладает множеством разных коннотаций. Однако наиболее распространенное его употребление связано с его функционированием в языковом пространстве, а точнее, в пространстве межъязыковой коммуникации. С лингвистической точки зрения, многие переводческие школы по-разному определяют точность перевода, отношение оригинала и переводного текста, а также по-своему подходят к определению перевода. Одним из таковых подходов является определение перевода, предложенное Р. Якобсоном. Он рассматривает перевод как перекодирование, как передачу смысла вербального знака в другой знаковой системе. Такой подход не отрицает наличие перевода внутри одного языка, т. е. между различными языковыми ситуациями. Р. Якобсон предложил рассматривать три разных вида перевода: межъязыковой перевод, внутриязыковой перевод и перевод между вербальной и невербальной коммуникативными 
системами ${ }^{1}$. Значение термина «перевод» расширяется, что позволяет обнаружить механику переноса смысла в различных языковых ситуациях, в том числе и внутри одного языка.

Такой лингвосемиотический подход к анализу перевода позволяет выявить внутреннюю механику переводческой деятельности, которая к тому же представляет собой достаточно противоречивое явление. Особенно остро эта противоречивость проявляется в межъязыковом переводе. Якобсон указывает на то, что полностью, без остатка, перевести какую-либо смысловую единицу одного языка на другой невозможно [11, с. 262]. Это означает, что между разными языками сохраняется некий смысловой зазор. Наличие таких межъязыковых лакун означает, что процессу перевода доступно все, но интерпретация различных знаков будет требовать различной степени учета социокультурного контекста употребления этого знака. Невозможность сохранения эквивалентности знаковых систем определяется Якобсоном как «кардинальная проблема языка и центральная проблема лингвистики» [11, с. 263]. Однако последствия этой проблемы не ограничиваются только лингвистической сферой функционирования перевода, но распространяются на возможность и условия самой коммуникации.

Перевод как необходимый механизм для производства социального выступает в концепции Ж. Деррида. Для него перевод представляет собой «необходимое и невозможное» [3, с. 18] одновременно. Перевод становится необходимым для достижения взаимопонимания после «крушения Вавилонской башни», однако в то же самое время сохраняется его невозможность из-за неустранимой неэквивалентности языков. Перевод с одного языка на другой фактически представляет собой деконструкцию иностранной фразы и реконструирование ее на другом языке. Деятельность переводчика, таким образом, разбивается на несколько этапов. Первый этап можно назвать герменевтическим, так как он представляет собой процесс интерпретации знаков исходного языка. На втором этапе задача переводчика заключается в подборе наиболее подходящего эквивалента знака исходного языка. Однако переведенная фраза не будет абсолютна равной оригиналу, так как никакой язык полностью не равен другому. Таким образом, в концепции перевода Деррида, также как в лингвистической теории Якобсона, можно проследить удержание проблемы неэквивалентности языков. Н. С. Автономова отмечает, что для Деррида важно сохранить это неустранимое неравенство, ведь именно различие обеспечивает возможность диалога, ответственности, социальности [1, с. 172]. Вводя концепт различия, Деррида тем самым очерчивает границы человеческого, отделяя его от животного и божественного. Культура, которая всецело принадлежит человеку, основывается на различии. Различие лежит в ее фундаменте уже хотя бы потому, что дихотомия природного и культурного строго очерчивает границы культуры. Становление человека человеком культурным

\footnotetext{
1 Якобсон Р. О лингвистических аспектах перевода // Избранные труды. Москва, 1985. С. 362. Перевод внутри одного языка присутствует и в социолингвистических концепциях. Например, в социолингвистической типологии А. Д. Швейцера и Л. Б. Никольского языковые ситуации, в которых используется перевод внутри одного языка, называются эндоглоссными. (См.: Швейцер А. Б., Никольский Л. Б. Введение в социолингвистику. Москва, 1978).
} 
также сопровождается усвоением своего тотального различения с другим [1, c. 372]. Различие знаковых систем, таким образом, становится необходимым основанием самой возможности коммуникации. Перевод теперь играет роль посредника, цель которого заключается в преодолении разрыва между различными системами знаков. Однако эта функция сопровождается сохранением неустранимого различия семиотических систем.

Перевод в межкультурной коммуникации: постколониальный взгляд

Наиболее остро проблема несоизмеримости языков проявляется в коммуникативном поле межъязыковового и межкультурного пространств. В настоящее время доминирующую позицию занимает дискурс плюральности, декларирующий равенство культур. Конец существования последней колонии становится точкой отсчета нового постколониального периода истории. Многие теоретики постколониализма связывают начало этого этапа с концом модерна [9, 13]. Новый постсовременный мир не конструируется посредством больших нарративов модерна, он производит свои метарассказы, один из которых - о равенстве культур. Однако провозглашение конца модерна не означает конец колонизации: она все также продолжает существовать, но в ином формате. Это означает, что колониализм перерастает из определенного набора политических действий в идеологию, определяющую способы взаимоотношения культур. Модель центрпериферия образует иерархию, которая изначально строится на разнообразии, многочисленности культурных форм. Однако это многообразие должно исчезнуть. Западная доминантная культура стремится к тому, чтобы выстроить гомогенное пространство, комфортное для нее самой. При этом колонизируемый субъект должен лишиться своей культуры, а затем и субъектности. Такое однородное пространство достигается за счет преодоления культурного многообразия. С. Бенхабиб говорит, что универсализация всегда есть следствие попытки объяснения другого, незнакомого. Такие способы выстраивания межкультурных коммуникаций неизбежно приводят к конфронтации, к разделению на объясняющих и объясняемых [2, с. 61]. Процесс объяснения подразумевает, что нечто чужое становится своим, подчиняется. С. Бенхабиб утверждает, что каждая культура это не закрытая монада, которая не имеет сообщения с внешним миром, а, значит, для того чтобы достичь взаимопонимания, необходимо существование такого однородного пространства с равными возможностями для участия всех культур. Тем не менее проблема заключается в том, что выбор способа создания самого этого пространства и языка выстраивания диалога будет очевиден — это язык западной доминантной культуры.

Предложенная М. Толстановой концепция транскультурации вскрывает проблему перевода и языковой иерархии [10]. Колониальность задает однонаправленный вектор культурного и эпистемологического перевода. Это означает, что эпистемологические системы локальных (колониальных) культур воспринимаются как своего рода экзотические рудименты. Существует только одна легальная эпистемология на язык, которой необходимо осуществлять перевод способов познания всех остальных культур. Такой перевод искажал понимание многих культурных особенностей и способствовал возникновению колониальности знания. Ориенталистическое представление о Востоке в полной мере иллюстрирует такой однонаправленный перевод. Романтизированное представление о Востоке, 
которое закрепилось в основных нарративах модерна, свидетельствует о том, что доминирующая эпистемологическая система видит в восточном культурном конструкте лишь объект исследования. Конечно, нельзя не заметить, что такой культурно-эпистемологический перевод возможен и в обратном направлении. Тем не менее такой переводческий вектор приобретает статус локального явления и не рассматривается в качестве основного.

Языковая иерархия сопровождает проблему перевода в условиях колониализма. «Западноевропейские языки (прежде всего английский, французский и немецкий) превратились в языки науки, знания, философии и утверждения модерности, а остальные были сведены к роли языков культуры и религии и к области пассивных реципиентов знаний и наук, генерирующихся в Западной Европе и Северной Америке» [10, с. 9]. Такое разделение языков, закрепление за ними особой роли отсылает к описанному Ж. Деррида логоцентризму. В рамках логоцентристской эпистемы преимущество отдается алфавитным европейским языкам [4, с. 229], в то время как неалфавитные языки считаются неприспособленными для науки. Тем самым такая языковая иерархия и односторонний межкультурный перевод способствовали эпистемологическому порабощению и укреплению модели центр-периферия.

При переводе с одного языка на другой остается белое пятно непонятого, такого, что нельзя с точностью передать на другом языке. В этом зазоре и располагается та самая уникальность и неповторимость каждой культуры. Этот непереводимый остаток является своего рода залогом сохранности каждой культуры. Таким образом, наличие перевода позволяет сохранять нерушимую границу между культурами. Призванный разрушать различные культурные и языковые барьеры перевод превращается в единственного хранителя нерушимости этих границ. В этих противоречивых функциях перевода проявляется его парадоксальность. Перевод одновременно является медиатором и границей двух языков и культур. Благодаря переводу сохраняется возможность конструирования коммуникативного пространства разных культур. При этом перевод выступает своего рода границей, которая сохраняет уникальность культур, препятствуя универсализации.

Неэквивалентность языковых значений и структур, которая порождает противоречивость перевода и как следствие самой коммуникации, пытались преодолеть многие авторы. Одним из наиболее распространенных способов преодоления языковой несоизмеримости является создание единого универсального языка. Ностальгией по единому языку буквально пропитана вся западная культурная традиция. В разные периоды можно обнаружить множество попыток создания единого языка всего человечества. Одним из таких примеров может выступать проект Лейбница по исследованию китайского языка [12, с. 40], который казался ему идеальным претендентом на то, чтобы стать универсальным языком. Китайский язык привлекал Лейбница потому, что в нем он видел чистое письмо, которое никак не соотносится со звуком ${ }^{1}$. На тот момент китайский язык именно так и представлялся всем исследова-

${ }^{1}$ Однако на самом деле все обстоит несколько иначе. В китайском языке существуют шесть категорий иероглифов. Одна из этих категорий - фонетические составные иероглифы или фоноидеограммы (синшэнвэньизы), которые состоят из двух частей: клю- 
телям-востоковедам. Эта кажущаяся разделенность и привлекла Лейбница, видевшего в китайском языке универсальность, которая может позволить в итоге заменить рассуждение исчислением. В этом случае перевод теряет свою значимость, становится ненужным, что, на первый взгляд, означает снятие проблемы противоречивости перевода в межкультурной коммуникации. Однако при более детальном анализе становится очевидно, что подобная унификация языкового пространства не решает проблему эпистемологической деколонизации, независимо от того, будет ли универсальный язык искусственным или выбран из уже существующих. Любая унификация языкового поля приводит к универсализации эпистемических структур, что в конечном итоге провоцирует отказ от плюрализма в культурной, социальной и политической сферах.

Перевод в системе социиальных связей

Рассматривая перевод в коммуникативном поле межкультурной коммуникации, противоречивость перевода начинает казаться непреодолимой. Однако, как показал Р. Якобсон, перевод можно рассматривать не только с точки зрения его межъязыкового функционирования, но и с точки зрения его действия внутри одного языка. В этом плане перевод представляет собой не только перекодировку смысла какого-либо текста, но и перенос этого смысла в другую языковую ситуацию. Именно в таком значении термин «перевод» использует Б. Латур [6, с. 192]. Он расширяет его значение, что позволяет видеть перевод не только в качестве лингвистического явления, но и как необходимый механизм функционирования общества вообще.

Б. Латур анализирует механику работы Л. Пастера, который проводил исследования по выяснению причин заболеваемости коров сибирской язвой по разработке вакцины от этого заболевания. Наиболее значимые результаты в этом исследовании были достигнуты благодаря экспериментам в Пуйи-ле-Фор в 1881 г. Перед Пастером стояла непростая задача, которая заключалась в необходимости убедить принять его точку зрения людей, деятельность которых лишь косвенно была связана с микробиологией и лабораторными исследованиями. Пастер должен был объяснить фермерам и представителям администрации, что, пренебрегая правилами антисептики, они подвергают опасности не только животных, но и многих людей. С точки зрения Латура, успех Пастера можно объяснить тем, что ему удалось точно сопоставить свои исследовательские интересы и интересы представителей сельского хозяйства, благодаря чему его вакцина и сама процедура вакцинирования стали необходимыми элементами социокультурного развития общества.

Анализируя работу Л. Пастера, Латур приходит к выводу, что задача ученого состоит в переводе чего-то нового и неизвестного на общедоступный язык. Ре-

ча и фонетики. Ключ передает значение иероглифа, а фонетик - его звучание. Таких иероглифов большинство в китайском языке, хотя со временем произношение многих слов сильно изменилось, и теперь многие иероглифы при общности фонетика произносятся по-разному. Еще одна категория - фонетические заимствования (цзяцзевэньизы). Таких иероглифов сравнительно мало, и, как правило, это слова, пришедшие в китайский из иностранных языков. (См. Духовная культура Китая: энциклопедия: в 5 т. / гл. ред. М. Л. Титаренко. М., 2006. Т. 3. С. 734). 
зультаты производства нового знания нуждаются в расшифровке, в противном случае они не будут работать. Чтобы научное изобретение стало социально значимым открытием, необходимо убедить в этом остальных, осуществив перевод интересов (в частности перевод научных интересов на язык других агентов социального взаимодействия) [5]. Посредством перевода интересов ученые образуют длинные сети, в которых важными элементами являются не только люди, но и вещи. Эти сети распространяются далеко за пределы лабораторий, а значит, и перевод также используется далеко за пределами научного сообщества. Стратегии перевода представляют собой различные уловки, к которым с необходимостью прибегает актор для реализации своих целей [6, с. 179]. Все эти стратегии и тактики перевода отличаются друг от друга структурно, но имеют общую цель - интерпретация своих интересов с точки зрения определенной коммуникативной ситуации. Таким образом, социальное пространство представляется совокупностью противоречивых интересов, а перевод представляется способом их упорядочивания и выстраивания коммуникационного поля. Перевод как убеждение другого актора в следовании своим интересам способствует установлению социальных связей, распространению сетей.

Таким образом, перевод в системе социальных связей сохраняет свою функцию медиатора. Перевод интересов означает перевод между разными коммуникативными ситуациями, в которых акторы вынуждены менять свое речевое поведение, адаптироваться к меняющимся условиям. Эта функция перевода обеспечивает равенство всех участников коммуникации. Латур в своих работах также неоднократно подчеркивает, что все акторы, в том числе и вещи, действуют в равных условиях $[6,8]$. Попытка Латура уравнять акторов, под которыми он понимает и человека, и нечеловеческие существа (животные, природные объекты) и вещи, имеет далеко идущие последствия. Это приводит к радикальному пересмотру конституции модерна [7, с. 107-109], главной идеей которой было любой ценой сохранить непреодолимую границу между обществом (миром людей) и природой. Перевод в этом плане приобретает особую роль: он становится связующим звеном между противоположными мирами. Благодаря переводу обнаруживается условность этой границы, а также искусственность разделения законов природы и мира людей. Эти выводы нашли продолжение в социальнофилософских концепциях, поднимающих экологическую проблематику.

Однако посредническая функция перевода, приводящая к равенству акторов, сопровождается тем, что всегда один актор будет говорить за другого. Таким способом Латур описывает роль представителя [6, с. 124]. Применительно к научным исследованиям значение представителя кажется бесспорным: исследователь всегда говорит за исследуемый предмет. Представительство в рамках общественных отношений также можно обнаружить при любом культурном или политическом устройстве общества. Повсеместность представительства (высказывания за другого), проникновение его в саму ткань социального устройства говорят об устойчивости этой структуры. В этом случае перевод, который осуществляется между различными акторами в процессе их коммуникации друг с другом, выполняет функцию разделителя. Он служит своего рода границей, показывающей различие интересов участников социального действия. Такое разделение также направлено на обеспечение циркуляции властных отношений на 
микроуровне. Это означает, что задача каждого актора - убедить другого следовать за ним, чтобы реализовать свои интересы. Для этого в процессе перевода интересов (что и означает сам процесс убеждения) будут реализовываться отношения власти и подчинения одного актора социального действия другому.

Заключение

Перевод, таким образом, можно описать как механизм, который действует не только при межкультурной, межъязыковой коммуникации, но и внутри одного языка. В обоих случаях функции перевода будут носить противоречивый характер. С одной стороны, перевод можно рассматривать в качестве медиатора, который соединяет разных акторов социального действия, участников межкультурной коммуникации. В обоих случаях благодаря переводу реализуется сама возможность кооперации. Однако, с другой стороны, перевод выступает в роли разделителя, границы, которую невозможно полностью устранить. Эта граница все же не отрицает возможность полноценного процесса коммуникации. На уровне межкультурного взаимодействия она позволяет сохранить уникальность каждой культуры, в то время как на уровне социального взаимодействия акторов она позволяет реализовывать цели.

Можно сказать, что основное значение такой противоречивости функций перевода заключается в сохранении возможности самой коммуникации. Постколониальная ситуация наглядно показывает, что навязываемая логоцентристская эпистемологическая система осуществляет однонаправленный перевод: единственная легальная интерпретация возможна только в западной культурносемиотической системе. Однако перевод сохраняет многообразие направленности коммуникационных векторов. При этом перевод в системе социального взаимодействия показывает, что занятие властной позиции носит условный характер, так как в любой момент сохраняется возможность для реализации своих интересов актора, ранее занимающего подчиненное положение.

Литература

1. Автономова Н. С. Познание и перевод. Опыты философии языка. Москва; СанктПетербург: Центр гуманитарных инициатив, 2017. 736 с. Текст: непосредственный.

2. Бенхабиб С. Притязания культур. Равенство и разнообразие в глобальную эпоху. Москва: Логос, 2003. 350 с. Текст: непосредственный.

3. Деррида Ж. Вокруг Вавилонских башен. Санкт-Петербург: Machina, 2012. 118 c. Текст: непосредственный.

4. Деррида Ж. О грамматологии. Москва: Ad Marginem, 2000. 512 с. Текст: непосредственный.

5. Латур Б. Дайте мне лабораторию и я переверну мир // Логос. 2002. № 5-6(35). C. 1-32. Текст: непосредственный.

6. Латур Б. Наука в действии: следуя за учеными и инженерами внутри общества. Санкт-Петербург: Изд-во Европейского ун-та в Санкт-Петербурге, 2013. 414 с. Текст: непосредственный.

7. Латур Б. Нового времени не было. Эссе по симметричной антропологии. СанктПетербург: Изд-во Европейского ун-та в Санкт-Петербурге, 2006. 240 с. Текст: непосредственный.

8. Латур Б. Пастер: война и мир микробов, с приложением «Несводимого». СанктПетербург: Изд-во Европейского ун-та в СПб, 2015. 316 с. Текст: непосредственный. 
9. Толстанова М. В. Пограничное (со)знание / мышление / эстезис на пути к трансмодерному миру // Общественные науки и современность. 2012. № 6. С. 155-165. Текст: непосредственный.

10. Толстанова М. В. Транскультурация как новая эпистема эпохи глобализации // Вестник Российского университета Дружбы народов. 2006. № 2(12). 5-16 с. Текст: непосредственный.

11. Якобсон Р. О лингвистических аспектах перевода / Избранные труды. Москва: Прогресс, 1985. 460 с. Текст: непосредственный.

12. Яковлев М. В. Предисловие // Лейбниц Г. В. Письма и эссе о китайской философии и двоичной системе исчисления. Москва, 2005. С. 404 с. Текст: непосредственный.

13. Mignolo W. The darker side of Western modernity: global futures, decolonial options. Duke University Press. 2011. 410 p.

Статья поступила в редакцию 10.11.2021; одобрена после рецензирования 15.11.2021; принята к публикациии 15.11.2021.

\title{
FUNCTIONAL CONTRADICTIONS OF TRANSLATION IN SOCIOCULTURAL PRACTICES
}

\author{
Anna A. Volkova \\ Research Assistant, \\ Russian State University for the Humanities \\ 6 Miusskaya Square, Moscow 125993, Russia \\ mymailmymail1994@mail.ru
}

Abstract. The article considers the functions of translation in intercultural, interlinguistic forms of communication, and in the system of social relations. Postcolonial optics allows us to consider the functionality of translation in terms of linguistic incommensurability. Intercultural communication demonstrates the differentiating function of translation. Considering the effect of translation in the system of social ties, we trace the opposite function of translation: the possibility of building a single communicative space with a difference in the interests of the participants in communication. The inconsistency of translation functions lies in the fact that, on the one hand, translation facilitates interaction, and, on the other hand, it functions as a border separating the participants in the communication process. Nevertheless, the multidirectionality of translation functions contributes to the preservation of the possibility of communication itself both in the conditions of inter-lingual communication, and within one language.

Keywords: translation, communication, contradictory functions of translation, translation of interests, epistemological translation.

\section{For citation}

Volkova A. A. Functional Contradictions of Translation in Sociocultural Practices. Bulletin of Buryat State University. Philosophy. 2021; 4: 62-69.

The article was submitted 10.11.2021; approved after reviewing 15.11.2021; accepted for publication 15.11.2021. 